\title{
Ten health stories that mattered: Feb. 10-14
}

- Canadians face patchwork access to screening for medical conditions depending on where they live, as authorities offer conflicting recommendations about who, when and what to screen for, and the responsibility for decision-making remains unclear, reports the Health Council of Canada.

- A retired marriage counsellor is offering nose jobs and "vaginal beautifications" at her laser clinic in Ottawa, Ontario - despite protests from the College of Physicians and Surgeons of Ontario. The woman, who doesn't claim to be a doctor, says she obtains drugs for local anesthesia from an unnamed physician who is not present when she performs the procedures.

- A study of nearly 90000 Canadian women shows that mammography doesn't reduce breast cancer deaths and offers no survival advantage over physical breast exams for middle-aged women. Researchers compared mammography versus no mammography in women aged 40 59 and found that the number of deaths was virtually the same for both groups, while $22 \%$ of the mammography-detected tumours were "over-diagnosed."
- This year's flu shot offered good protection to those who received it, according to a Canadian study. The vaccine appeared to be about $71 \%$ effective against all flu strains, and $74 \%$ effective against H1N1.

- A British Columbia hospital has delivered the baby of a brain-dead woman, whose body was kept on lifesupport in a bid to save the child's life. Life support was withdrawn after the cesarean delivery.

- Nova Scotia is considering a ban on using e-cigarettes in public places, citing concerns that smokers are using them to get around smoking bans in restaurants, shopping malls and other public areas.

- Alberta Health Services is withholding wait times data in order to save face, Alberta Liberal leader Dr. Raj Sherman charged at a press conference. He unveiled a quarterly report obtained through an access-to-information request that shows a slight decrease in patients cleared from emergency departments within eight hours, down $1 \%$ from last year to $47 \%$ - a measure that's missing from public reports.

- Teen girls with a major mental health disorder are three times more likely to get pregnant than those without a mental illness, an Ontario study reveals. Although the birth rates for both groups have dropped over time, the gap between them appears to be widening. Among girls with a major mental illness, live births decreased only $14 \%$ during the 10 -year study, compared to $22 \%$ among those unaffected by psychiatric illness.

- A diet based on food harvested or hunted locally in Nunavut could be the answer to food insecurity faced by $70 \%$ of all households in the territory, reported Action Canada. Local food consumption can be increased by improving hunting capacity, food processing and distribution, the group urged.

- The Professional Institute of the Public Service of Canada predicts the federal government will cut \$2.6 billion and 5064 jobs from 10 science-based federal departments between 2013 and 2016. In a report, the union representing scientists and professional public employees catalogued cuts already made to top scientists from the federal payroll, science programs and budget. Lauren Vogel, CMAJ

CMAJ 2014. DOI:10.1503/cmaj.109-4729 